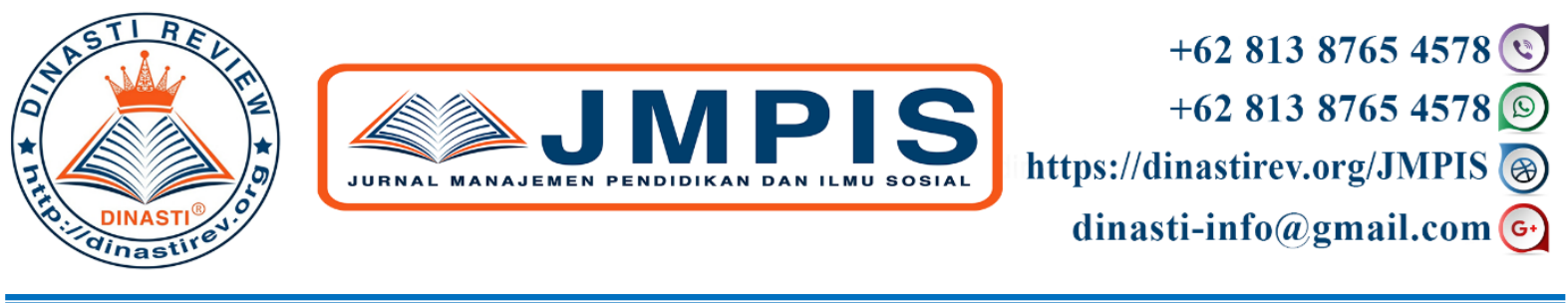

\title{
PENGARUH PROFITABILITAS, UKURAN PERUSAHAAN DAN CAPITAL INTENSITY TERHADAP TAX AVOIDANCE
}

Vani Mailia'), Apollow

${ }^{1,2)}$ Jurusan Akuntansi, Fakultas Ekonomi dan Bisnis Universitas Mercu Buana

\begin{tabular}{|c|c|}
\hline $\begin{array}{c}\text { ARTICLE INFORMATION } \\
\text { Received: } 27 \text { April } 2020 \\
\text { Revised: 6 Mei } 2020 \\
\text { Issued: } 12 \text { Mei } 2020 \\
\text { Corresponding author: first author } \\
\text { E-mail: } \\
\text { 43215120342@student.mercubuana.ac.id } \\
\text { mailiavani25@gmail.com } \\
\text { apollo@mercubuana.ac.id }\end{array}$ & $\begin{array}{l}\text { Abstrak: Tujuan dari penelitian ini adalah untuk } \\
\text { mengetahui pengaruh profitabilitas, ukuran } \\
\text { perusahaan dan capital intensity terhadap tax } \\
\text { avoidance. Pemilihan sampel menggunakan } \\
\text { metode purposive sampling. Penelitian ini } \\
\text { menggunakan } 26 \text { sampel perusahaan dengan } \\
\text { periode pengamatan 2014-2018 dengan } 122 \\
\text { laporan keuangan perusahaan manufaktur pada } \\
\text { sektor industri barang konsumsi di Bursa Efek } \\
\text { Indonesia. Metode statistik yang digunakan adalah } \\
\text { analisis regresi linear berganda. Hasil uji regresi } \\
\text { linear berganda menunjukkan bahwa profitabilitas } \\
\text { tidak berpengaruh terhadap tax avoidance. } \\
\text { Sedangkan ukuran perusahaan dan capital } \\
\text { intensity berpengaruh terhadap tax avoidance. } \\
\text { Kata Kunci: Profitabilitas, Ukuran Perusahaan, } \\
\text { Capital Intensity, Tax Avoidance }\end{array}$ \\
\hline
\end{tabular}

\section{PENDAHULUAN}

Pajak merupakan suatu komponen yang tidak dapat dipisahkan antara kegiatan usaha perusahaan dengan Pemerintah karena pajak menimbulkan kewajiban bagi perusahaan untuk membayar sejumlah dana tertentu kepada negara. Perusahaan dapat merencanakan pajak dalam jumlah minimum tanpa melanggar peraturan perpajakan yang berlaku yang disebut sebagai tax planning. Tujuan dari tax planning adalah memperkecil jumlah pajak yang akan dibayarkan ke Pemerintah dengan cara mengecilkan laba, mempekerjakan tenaga ahli dibidang perpajakan dan memanfaatkan beban depresiasi atas aktiva tetap perusahaan. Tindakan tersebut disebut sebagai tax avoidance yaitu upaya mengefisienkan.beban pajak dengan cara menghindari pengenaan pajak dengan mengarahkannya pada transaksi bukan objek pajak (Pohan, 2013). 
Salah satu fenomena tax avoidance yang terjadi di Indonesia adalah yang dilakukan oleh PT.British American Tobacco. Perusahaan tembakau milik British American Tobacco (BAT) dilaporkan oleh lembaga Tax Justice Network telah melakukan penghindaran pajak melalui PT. Bentoel Internasional Investama dengan cara membayar bunga pinjaman dan royalti sehinggga dampak dari kegiatan tersebut negara mengalami kerugian US \$14 juta per saham (www.kontan.com.id, 2019).

\section{KAJIAN PUSTAKA}

\section{Teori Agensi}

(Jensen, M and Meckling, 1976) menjelaskan hubungan antara manajemen (agent) dan pemegang saham (principal). Keterkaitan teori agensi terhadap tax avoidance yang dipengaruhi oleh agency problem yang terjadi akibat dari perbedaan kepentingan antara manajemen dan pemegang saham.

\section{Teori Akuntansi Positif}

(Watts and Zimmerman, 1990) menjelaskan teori akuntansi positif memiliki tiga motivasi salah satunya teori biaya politik.Teori biaya politik menggambarkan perusahaan besar akan melakukan lebih banyak kebijakan yang akan menyebabkan laba menurun dengan maksud mengurangi efek politis.

\section{Tax Avoidance}

Erly Suandy (2017 : 20) mengungkapkan tax avoidance adalah suatu usaha pengurang secara legal yang dilakukan dengan cara memanfaatkan ketentuan-ketentuan dibidang perpajakan secara optimal.

\section{Profitabilitas}

Sakevych and Patrick (2015 : 29) mengungkapkan Profitability means the ability of a company to earn a profit.Firm's profitability is very important both for stockholders and creditos because revenue in the form of dividends is being derived from profit, as well as profits are one of funds for covering debts.Profitability ratio analysis is a good way to measure company's performance.

\section{Ukuran Perusahaan}

Hery (2017:3) menyatakan ukuran perusahaan adalah suatu skala untuk mengklasifikasikan besar kecilnya perusahaan menurut berbagai cara, antara lain dengan total aset, total penjualan, nilai pasar saham, dan sebagainya.

\section{Capital Intensity}

Delgado (2014:490) capital intensity shows the composition of assets that will impact the effective tax rate, especially fixed assets that will impact tax deductions from the resulting depreciation expense. 


\section{METODE PENELITIAN}

Metode yang digunakan dalam penelitian ini adalah analisis linear berganda dan menggunakan perhitungan ilmu statistik yaitu SPSS versi 21. Populasi dalam penelitian ini adalah perusahaan manufaktur sub sektor barang konsumsi tahun 2014-2018. Teknik pengambilan sampel dalam penelitian ini menggunakan metode purposive sampling, yaitu teknik penentuan sampel dengan pertimbangan tertentu pada periode tertentu. Data yang memenuhi kriteria yang ditetapkan diperoleh sebanyak 26 perusahaan. Data sekunder yang dibutuhkan dalam penelitian yaitu informasi keuangan dari laporan keuangan perusahaan yang termasuk dalam variabel yang diteliti yang diunduh melalui web Bursa Efek Indonesia yaitu www.idx.co.id dan web perusahaan.

HASIL DAN PEMBAHASAN

Hasil uji statistik dekskriptif

Tabel 1. Hasil Uji Statistik Deskriptif

Descriptive Statistics

\begin{tabular}{|l|r|r|r|r|r|}
\hline & \multicolumn{1}{|c|}{$\mathrm{N}$} & Minimum & Maximum & \multicolumn{1}{c|}{ Mean } & Std. Deviation \\
\hline ETR & 122 & .13 & .34 & .2552 & .03155 \\
ROA & 122 & .01 & .92 & .1332 & .12581 \\
SIZE & 122 & 25.80 & 32.20 & 28.9143 & 1.54477 \\
CIR & 122 & .05 & .89 & .3037 & .17985 \\
Valid N (listwise) & 122 & & & & \\
\hline
\end{tabular}

\section{Sumber : Output SPSS 21}

Dari hasil analisis menunjukkan bahwa tax avoidance memiliki nilai minimum sebesar 0.13, nilai maksimum 0.34, rata-rata (mean) sebesar 0.2552 dan nilai standar deviasi 0.03155 . Profitabilitas memiliki nilai minimum sebesar 0.01, nilai maksimum 0.92, rata-rata (mean) sebesar 0.1332 dan nilai standar deviasi 0.12581 . Ukuran perusahaan memiliki nilai minimum sebesar 25.80, nilai maksimum 32.20, rata-rata (mean) sebesar 28.9143 dan nilai standar deviasi 1.54477. Capital intensity memiliki nilai minimum sebesar 0.05, nilai maksimum 0.89, rata-rata (mean) sebesar 0.3037 dan nilai standar deviasi 0.17985 . 


\section{Hasil uji normalitas}

Tabel 2. Hasil Uji Normalitas

\section{One-Sample Kolmogorov-Smirnov Test}

\begin{tabular}{|ll|r|}
\hline & & \multicolumn{2}{|c|}{$\begin{array}{c}\text { Unstandardized } \\
\text { Residual }\end{array}$} \\
\hline $\mathrm{N}$ & & 122 \\
Normal Parameters & Mean & .0000000 \\
& Std. Deviation & .02985741 \\
Most Extreme Differences & Absolute & .082 \\
& Positive & .082 \\
Kolmogorov-Smirnov Z & Negative & -.077 \\
Asymp. Sig. (2-tailed) & & .905 \\
\end{tabular}

a. Test distribution is Normal.

b. Calculated from data.

\section{Sumber : Output SPSS 21}

Berdasarkan tabel diatas, nilai Asymp. Sig (2-tailed) sebesar 0,385>0,05 menunjukkan hasil bahwa data penelitian berdistribusi normal.

\section{Hasil uji multikolinieritas}

Tabel 3. Hasil Uji Multikolinieritas

\begin{tabular}{|l|l|r|r|}
\hline \multicolumn{2}{|c|}{ Model } & \multicolumn{2}{|c|}{ Coefficients $^{\mathrm{a}}$} \\
\cline { 3 - 4 } \multicolumn{2}{|l|}{ Collinearity Statistics } \\
\hline \multirow{4}{*}{1} & ROA & Tolerance & \multicolumn{2}{c|}{ VIF } \\
\cline { 3 - 5 } & SIZE & .919 & 1.088 \\
& CIR & .961 & 1.041 \\
\hline
\end{tabular}

a. Dependent Variable: ETR

\section{Sumber : Output SPSS 21}

Berdasarkan tabel diatas, semua nilai tolerance $>0,10$ dan nilai VIF $<10$, dapat disimpulkan bahwa model regresi tidak mengandung multikolinieritas. 


\section{Hasil uji autokorelasi}

Tabel 4. Hasil Uji Multikolinieritas

Model Summary ${ }^{b}$

\begin{tabular}{|l|r|r|r|r|r|}
\hline Model & \multicolumn{1}{|c|}{$\mathrm{R}$} & R Square & \multicolumn{1}{c|}{$\begin{array}{c}\text { Adjusted R } \\
\text { Square }\end{array}$} & $\begin{array}{l}\text { Std. Error of the } \\
\text { Estimate }\end{array}$ & Durbin-Watson \\
\hline 1 & $.282^{\mathrm{a}}$ & .080 & .056 & .02938 & 1.923 \\
\hline
\end{tabular}

a. Predictors: (Constant), LAG_CIR, LAG_SIZE, LAG_ROA

b. Dependent Variable: LAG_ETR

\section{Sumber : Output SPSS 21}

Berdasarkan tabel diatas, Nilai Durbin-Watson yang dihasilkan yaitu sebesar 1.923, sedangkan nilai $\mathrm{dL}=1.653$ dan nilai $\mathrm{dU}=1.754$, sedangkan nilai 4 -dU $=2.347$. Nilai $\mathrm{d}$ yang dihasilkan terletak diantara batas atas atau upper bound (dU) dan (4-dU), maka autokorelasi = 0 , atau $1.754<1.923<2.347$. Maka hasil keputusannya adalah tidak ditolak hipotesis nol menyatakan tidak ada korelasi positif dan negative dalam model regresi.

\section{Hasil Uji Heteroskedastisitas}

Tabel 5. Hasil Uji Multikolinieritas

Coefficients $^{\mathbf{a}}$

\begin{tabular}{|c|c|c|c|c|c|c|}
\hline \multirow{2}{*}{\multicolumn{2}{|c|}{ Model }} & \multicolumn{2}{|c|}{$\begin{array}{c}\text { Unstandardized } \\
\text { Coefficients }\end{array}$} & \multirow{2}{*}{$\begin{array}{c}\text { Standardized } \\
\text { Coefficients } \\
\text { Beta }\end{array}$} & \multirow[t]{2}{*}{$\mathrm{t}$} & \multirow[t]{2}{*}{ Sig. } \\
\hline & & $\mathrm{B}$ & Std. Error & & & \\
\hline \multirow{4}{*}{1} & (Constant) & -1.633 & 4.351 & & -.375 & .708 \\
\hline & ROA & -1.192 & 1.857 & -.059 & -.642 & .522 \\
\hline & SIZE & -.267 & .149 & -.162 & -1.797 & .075 \\
\hline & CIR & 2.392 & 1.297 & .169 & 1.844 & .068 \\
\hline
\end{tabular}

a. Dependent Variable: LN_RESKUADRAT

\section{Sumber : Output SPSS 21}

Pada tabel diatas menunjukkan bahwa tidak terjadi heteroskedastisitas karena semua variabel nilai signifikannya $>0,05$. 


\section{Hasil Uji Koefisien Determinan}

Tabel 6. Hasil Uji Koefisien Determinan

\begin{tabular}{|l|r|r|r|r|r|}
\hline Model & R & R Square & $\begin{array}{c}\text { Adjusted R } \\
\text { Square }\end{array}$ & $\begin{array}{c}\text { Std. Error of the } \\
\text { Estimate }\end{array}$ & Durbin-Watson \\
\hline 1 & $.321^{\mathrm{a}}$ & .103 & .080 & .03025664 & 1.502 \\
\hline
\end{tabular}

a. Predictors: (Constant), CIR, SIZE, ROA

b. Dependent Variable: ETR

\section{Sumber : Output SPSS 21}

Berdasarkan tabel diatas, nilai adjusted $R$ square sebesar 0,080. Hal ini menunjukkan bahwa pengaruh variabel independen sebesar $8 \%$ terhadap variabel dependen. Dan sebanyak 92\% variabel dependen dipengaruhi oleh variabel lain diluar model penelitian.

\section{Hasil Uji Signifikan Simultan (Uji F)}

Tabel 7. Hasil Uji Koefisien Determinan

\begin{tabular}{|c|c|c|c|c|c|c|}
\hline \multicolumn{7}{|c|}{ ANOVA $^{a}$} \\
\hline & & $\begin{array}{l}\text { Sum of } \\
\text { Squares }\end{array}$ & $\mathrm{df}$ & $\begin{array}{c}\text { Mean } \\
\text { Square }\end{array}$ & $\mathrm{F}$ & Sig. \\
\hline \multirow{3}{*}{1} & Regression & .013 & 3 & \multirow{3}{*}{$\begin{array}{l}.004 \\
.001\end{array}$} & \multirow[t]{3}{*}{4.587} & \multirow[t]{3}{*}{$.004^{\mathrm{b}}$} \\
\hline & Residual & .108 & 118 & & & \\
\hline & Total & .120 & 121 & & & \\
\hline
\end{tabular}

a. Dependent Variable: ETR

b. Predictors: (Constant), CIR, SIZE, ROA

\section{Sumber : Output SPSS 21}

Berdasarkan tabel anova diatas, nilai Sig. sebesar 0,004<0,05, maka dapat disimpulkan bahwa profitabilitas, ukuran perusahaan dan capital intensity secara bersama-sama berpengaruh signifikan terhadap tax avoidance. 


\section{Hasil Uji Parsial t-Statistik}

Tabel 7. Hasil Uji t-Statistik

\begin{tabular}{|c|c|c|c|c|c|c|}
\hline \multirow{2}{*}{\multicolumn{2}{|c|}{ Model }} & \multicolumn{2}{|c|}{ Unstandardized Coefficients } & \multirow{2}{*}{$\begin{array}{c}\begin{array}{c}\text { Standardized } \\
\text { Coefficients }\end{array} \\
\text { Beta } \\
\end{array}$} & \multirow[t]{2}{*}{$\mathrm{t}$} & \multirow{2}{*}{ Sig. } \\
\hline & & $\mathrm{B}$ & Std. Error & & & \\
\hline \multirow{4}{*}{1} & (Constant) & .092 & .053 & & 1.736 & .085 \\
\hline & ROA & -.018 & .023 & -.071 & -.790 & .431 \\
\hline & SIZE & .005 & .002 & .262 & 2.954 & .004 \\
\hline & CIR & .037 & .016 & .211 & 2.350 & .020 \\
\hline
\end{tabular}

\section{Sumber : Output SPSS 21}

Berdasarkan tabel diatas, profitabilitas memiliki nilai signifikan 0,431, maka dapat disimpulkan profitabilitas tidak berpengaruh signifikan terhadap tax avoidance. Ukuran perusahaan memiliki nilai signifikan 0,004 dan capital intensity memiliki nilai signifikan 0,020 maka dapat disimpulkan ukuran perusahaan dan capital intensity berpengaruh signifikan terhadap tax avoidance.

\section{PEMBAHASAN}

Dari hasil uji pada penelitian yang dilakukan membuktikan profitabilitas tidak berpengaruh signifikan terhadap tax avoidance. Penelitian ini sejalan dengan penelitian yang dilakukan oleh (Alfina, 2016) karena perusahaan dengan tingkat ROA yang tinggi dapat mengatur pendapatannya sehingga cenderung mematuhi kewajibannya untuk membayar pajak. Hal ini bertolak belakang dengan teori agensi yang menjelaskan bahwa pemegang saham menginginkan biaya pajak yang rendah.

Selanjutnya ukuran perusahaan berpengaruh signifikan terhadap tax avoidance. Penelitian ini sejalan dengan (Swingly, 2015) hal ini sesuai dengan teori biaya politik dimana motivasi biaya politik adalah perusahaan besar akan melakukan lebih banyak kebijakan yang akan menyebabkan laba menurun dengan maksud mengurangi efek politis seperti kebijakan untuk melakukan transfer pricing atau thin capitalization.

Dan yang terakhir capital intensity berpengaruh signifikan terhadap tax avoidance.Penelitian ini sejalan dengan (Dwiyanti, 2019). Hasil ini sesuai dengan teori biaya politik yang menjelaskan perusahaan besar cenderung menggunakan prosedur akuntansi dengan menurunkan laba untuk tujuan pembebanan pajak yang tinggi dengan cara menginvestasikan laba berupa asset tetap yang nantinya akan dilakukan depresiasi dan menimbulkan beban depresiasi pada tiap akhir periode untuk dapat mengurangi laba perusahaan. 


\section{KESIMPULAN DAN SARAN}

\section{Kesimpulan}

Dari hasil penelitian menunjukkan bahwa variabel profitabilitas tidak berpengaruh signifikan terhadap tax avoidance. Ukuran perusahaan dan capital intensity berpengaruh signifikan terhadap tax avoidance.

\section{Saran}

Untuk peneliti selanjutnya disarankan menambah variabel lainnya dan menambah sampel pada sektor lain, sehingga dapat menggambarkan faktor-faktor apa saja yang dapat mempengaruhi tax avoidance.

\section{DAFTAR PUSTAKA}

Alfina, I. T. , Siti N. , Anita W. (2016). The Influence of Probability, Leverage, Independent Commissioner, and Company Size to Tax Avoidance. Journal The Second International Conference on Technology, Education and Social Science, pp 102-106

Daito, A. (2007). Metodologi Penelitian Penyusunan Skripsi. Tesis/Disertasi., Jakarta., Universitas Budi Luhur

Daito, A (2011). Pencarian Ilmu Melalui Pendekatan Ontologi, Epistimologi, dan Aksiologi, Jakarta: Mitra Wacana Media

Delgado, F.J., E. F. Rodriguez, dan A. M. Arias. (2014). Effective Tax Rates in Corporate Taxation: a Quantile Regression for the EU. Im=nzinerine Ekonomika Engineering Economics, 25: 487-496

Dwiyanti, I. A. I., I K. Jati (2019). Pengaruh Profitabilitas, Capital Intensity, dan Inventory Intensity pada Penghindaran Pajak. E-Jurnal Akuntansi Universitas Udayana 27.3 Juni (2019) h:2293-2321

Hery. (2017). Kajian Riset Akuntansi. PT Grasindo.

Jensen, Michael C. dan W.H. Meckling. (1976). Theory of The Firm: Managerial Behavior, Agency Cost and Ownership Structure. Journal of Financial Economics3, pp: 305- 360.

Sakevych, A. dan Patrick K. (2015). An Introduction to the Financial Statement. Finstanon Books [Online] Tersedia: https://play.google.com/store/books/details?id=R5oTCwAAQBAJ

Suandy, Erly. (2017). Hukum Pajak. Yogyakarta: Salemba Empat.

Swingly, C. dan I M. S. (2015). Pengaruh Karakter Eksekutif, Komite Audit, Ukuran Perusahaan, Leverage dan Sales Growth pada Tax Avoidance. E-Jurnal Akuntansi Universitas Udayana 10.1 h:47-62.

Pohan, C. A. (2013). Manajemen Perpajakan Strategi Perencanaan Pajak dan Bisnis. PT Gramedia. 
Watss, R. L., and Zimmerman, J.L. (1990). Positive Accounting Theory : A Ten Year Perspective. American Association, 131-156

www.kontan.co.id. (2019) Tax Justice laporkan Bentoel lakukan penghindaran pajak, Indonesia rugi US\$ 14 juta https://www.google.com/amp/amp.kontan.co.id/news/tax-justice-laporkan-bentoel-lakukanpenghindaran-pajak-indonesia-rugi-rp-14-juta [17 Juni 2019] 